Original Article

\title{
Environmental factors associated with Dictyocaulus viviparus and Fasciola hepatica prevalence in dairy herds from Costa Rica
}

\author{
A.E. Jiménez-Rocha ${ }^{\mathrm{a}, *}$, S. Argüello-Vargas ${ }^{\mathrm{b}}$, J.J. Romero-Zuñiga ${ }^{\mathrm{c}}$, J.A. Sequeira-Avalos ${ }^{\mathrm{d}}$, G. Dolz ${ }^{\mathrm{c}}$, \\ V. Montenegro-Hidalgo ${ }^{\text {a }}$, T. Schnieder ${ }^{\mathrm{e} i}$ \\ a Laboratorio de Parasitología, Escuela de Medicina Veterinaria, Universidad Nacional, Costa Rica, P.O. Box 86-3000, Heredia, Costa Rica \\ b Posgrado Regional en Ciencias Veterinarias Tropicales, Universidad Nacional, Costa Rica, P.O. Box 86-3000, Heredia, Costa Rica \\ c Programa de Investigación en Medicina Poblacional, Escuela de Medicina Veterinaria, Universidad Nacional, Costa Rica, P.O. Box 86-3000, Heredia, Costa Rica \\ d Cooperativa de Productores de Leche Dos Pinos, RL. Alajuela, Costa Rica, P.O. Box, 179-4060, Alajuela, Costa Rica \\ e† Institute for Parasitology, University of Veterinary Medicine Hannover, Hannover, Germany
}

\section{A R T I C L E I N F O}

Keywords:

Prevalence

Milk

Dictyocaulus viviparus

Fasciola hepatica

\begin{abstract}
A B S T R A C T
Dictyocaulosis and fasciolosis are parasitic diseases that cause considerable economic losses for owners of farm animals worldwide, with special relevance on fasciolosis because it is an emerging zoonosis. Indirect diagnosis of these diseases through analyses of bulk milk tank samples has allowed carrying out large-scale prevalence studies, while the use of geographical information systems has helped to visualize and determine those variables that affect distribution of these pathogens. This study is intended to describe the spatial distribution of Dictyocaulus viviparus and Fasciola hepatica in dairy herds from Costa Rica, as well as their associated environmental factors. Bulk milk tank samples from 526 dairy herds in the three most important dairy regions of Costa Rica were analyzed using enzyme immunoassays. Results from the farms were subjected to spatial analyses using Holdridge's life zones, relief and soil type environmental layers. Of the total bulk milk tank samples analyzed, $3.8 \%(n=20)$ and $3.6 \%(n=19)$ were positive for $D$. viviparus and $F$. hepatica, respectively. Moran's I analysis revealed the existence of potential cluster (Moran's $I=1.789, \mathrm{z}=12.726 p<0.05$ ) for D. viviparus. Consequently, Getis-Ord General G analysis showed that the spatial distribution of positive farms in the dataset was clustered (Observed General $\mathrm{G}=0.015$, variance $=0.000001, \mathrm{z}=12.823, p<0.05$ ). No significant positive spatial autocorrelation (Moran's $I=0.038, \mathrm{z}=0.286, p>0.0 .5$ ) was observed for $F$. hepatica. Furthermore, a significant difference was detected in the spatial locations of both parasites (latitude $p<0.05$, longitude $p<0.05$ ), and about the spatial distribution of both $D$. viviparus negative and positive farms (latitude $p<0.05$, longitude $p<0.05$ ), as well as in $F$. hepatica negative and positive farms regarding on latitude $(p<0.05)$, but not on longitude $(p>0.05)$. In the case of environmental factors, significant differences were found for $D$. viviparus and $F$. hepatica with respect to types of soil, precipitation, altitudinal belts, life zones, biotemperature, and elevation.
\end{abstract}

\section{Introduction}

Bovine dictyocaulosis and fasciolosis are parasitic diseases that cause considerable economic losses in bovine herds (Wapenaar, 2011; Dank et al., 2015; Radfar et al., 2015; Rojas, 2015), and are caused by the Dictyocaulus viviparus nematode and the Fasciola hepatica digenea trematode; both parasites affect a wide range of domestic and wild animals (Issia et al., 2009; Dracz and Lima, 2014; Pyziel et al., 2015). Additionally, fasciolosis is well known as an emerging zoonotic disease (Olsen et al., 2015).

There are only a few reports on the economic losses caused by dictyocaulosis, estimations made in the United Kingdom in 2007, based on two dairy herds, indicate an average loss of US $\$ 22,852.60$ per farm (Holzhauer et al., 2011). On the other hand, in Costa Rica (2015), an outbreak of dictyocaulosis in 28 cows caused losses in milk production close to US $\$ 16,225.00$ (unpublished data). Regarding fasciolosis, Rojas (2015) estimated annual economic losses for US $\$ 67,313.00$ from viscera confiscations in class A slaughterhouses in Costa Rica. These losses are the result of milk and weight reduction, developmental delays and fertility-related problems, as well as the discarding of a great amount of livers affected in slaughterhouses (Das Chagas et al., 2011; Howell et al., 2015).

\footnotetext{
* Corresponding author.

E-mail addresses: ana.jimenez.rocha@una.cr, anajimenez@racsa.co.cr (A.E. Jiménez-Rocha).
} 
Worldwide, several studies have used geographical information systems (GIS) to determine the variables that affect distribution of dictyocaulosis and fasciolosis, as well as their relationship with environmental factors and management practices (Bennema et al., 2011; Kuerpick et al., 2013a; Schunn et al., 2013).

Different enzyme-linked immunosorbent assays (ELISAs) have been developed for serological diagnosis of $D$. viviparus and $F$. hepatica in bovines, using recombinant, somatic and excretory-secretory (ES) antigens (Schnieder, 1992; Cornelissen et al., 1997; Salimi-Bejestani et al., 2005; Kuerpick et al., 2013b; Schunn et al., 2012), as well as coproantigens to diagnose $F$. hepatica (Kajugu et al., 2015).

Bulk milk tank ELISA's have made possible to detect infections resulting from the exposure of dairy cattle to both agents, and they have been considered as highly useful diagnostic tools in large-scale prevalence studies or in epidemiological surveillance systems for monitoring herd health programs, given their quickness of use, low cost and high specificity (Sekiya et al., 2013). From 2005 to date, the use of ELISA on milk tank has been implemented in the diagnosis of $D$. viviparus and $F$. hepatica (Salimi-Bejestani et al., 2005; Bennema et al., 2009; Bloemhoff et al., 2015; Howell et al., 2015).

In Costa Rica, only a few studies have been carried out on the prevalence of $D$. viviparus in dairy cattle (Jiménez et al., 2007; Jiménez et al., 2008; Jiménez et al., 2010); likewise, studies with bovines and humans have emphasized the economic and zoonotic importance of fasciolosis in the counties of Turrialba and Pococí (Mora et al., 1980; Arroyo et al., 1981; Chang and Cartín, 1983; Alpízar et al., 2013). No studies have been carried out on bulk milk tank samples involving herds of all areas of our country using immunodiagnostic tests for $D$. viviparus and $F$. hepatica for epidemiological surveillance, nor geographic information systems (GIS) has been used for such purposes. Therefore, the objective of the present study was to describe the spatial distribution of $D$. viviparus and $F$. hepatica in dairy herds from Costa Rica, as well as associated environmental factors.

\section{Material and methods}

\subsection{Study population and type of study}

A cross-sectional study was carried out in a total of 526 specialized dairy farms, distributed in three regions of Costa Rica: Chorotega (101), Central (160) and North Huetar (265). They are considered specialized dairy farms, because they have mostly Holstein and Jersey cows, use a milking room with milking machines, pasture rotation, concentrated feed and nutritional supplements, artificial insemination, recording systems, and veterinary and other technical assistance.

\subsection{Milk samples}

Bulk milk tank samples were collected from each farm only once during October 2008. In farms with less than 50 dairy cows, the sample was taken at the end of the milking process; in other farms, samples were taken when 50 cows had been milked. The bulk milk tank mixer was activated for $3 \mathrm{~min}$ before the sample was taken. Milk samples were collected in boric acid $10 \%$.

\subsection{Serological analysis}

Once samples were in the laboratory, they were centrifuged at 2000 r.p.m. for $15 \mathrm{~min}$, fat was removed and milk was then sampled and stored at $-20{ }^{\circ} \mathrm{C}$ until assayed. Serum samples were analyzed at the Parasitology Institute of the Tiereräztliche Hochschule in Hannover, Germany, using the ELISA technique to detect D. viviparus and $F$. hepatica antibodies, using the major sperm protein recombinant and excretor-secretor products as antigens, respectively (Charlier et al., 2007; Von Holtum et al., 2008; Bennema et al., 2009; Fiedor et al., 2009).

\subsection{Spatial data management}

A database of $D$. viviparus and $F$. hepatica positive and negative farms was created, and all the farms were georeferenced at the location of the dairy facilities, using a Garmin model 12 XL GPS. The points representing the farms were overlaid in environmental layers obtained from the Costa Rican Digital Atlas (2014), using the Spatial Join command of Arc Gis 10.2. (ESRI, 2013). The environmental layers used were type of soils, relief (altitude) and Holdridge's life zones (Holdridge, 1978), all at a scale of 1:200.000. Life zone, annual precipitation $(\mathrm{mm})$, biotemperature $\left({ }^{\circ} \mathrm{C}\right)$ and altitudinal belts variables were used from Holdridge's life zones layer.

\subsection{Statistical analysis}

The global herd level prevalence for each parasite was calculated, as well as for co-infection and it was performed a comparison of percentages by region. Differences between positive and negative farms about longitude and latitude averages, between and among parasites were assessed by one-way ANOVA and a post-hoc Bonferroni test. Besides, a $\mathrm{Chi}^{2}$ test for multiple percentages comparison was performed. In this study, Moran's I was used as the measure of spatial autocorrelation for each species and Getis-Ord General G statistic as the measure of clustering of positive/negative farms. For all tests, a $p$-value of 0.05 was established as critical threshold of statistical significance.

\section{Results}

\subsection{Serology}

Out of the total (526) of bulk milk tank samples analyzed, a 3.9\% (20) and a $3.7 \%$ (19) were positive for $D$. viviparus and $F$. hepatica, respectively.

In the specific case of $D$. viviparus, frequencies by region showed that there were four positive farms in the Central region (4/161, $2.48 \%)$, three positive farms in the North Huetar region $(3 / 265$, $1.13 \%)$, while the Chorotega region showed the greatest percentage of positive farms $(13 / 101,12.87 \%)(p<0.05)$.

On the other hand, prevalence of $F$. hepatica did not show statistical differences between regions, although the Central region had a prevalence of $5.60 \%(9 / 161)$, which is slightly more than twice the prevalence found in the North Huetar region $(2.27 \%, 6 / 265)$; while the prevalence in the Chorotega region was 3.96\% (4/101) $(p>0.05)$.

Antibodies against both parasites were detected only in one of the 38 positive farms located in the Central region.

\subsection{Spatial occurrence of infected herds}

The spatial distribution of infective herds that were positive for $F$. hepatica and $D$. viviparus are shown in Fig. 1. A significant difference was observed in terms of the spatial location of both species in latitude $(p<0.05)$ and longitude $(p<0.05)$.

Significant positive spatial autocorrelation (Moran's $I=1.789$, $\mathrm{z}=12.726 p<0.05$ ) was observed for $D$. viviparus, revealing the existence of potential cluster. Getis-Ord General $\mathrm{G}$ analysis showed that the spatial distribution of positive farms in the dataset was clustered (Observed General $\mathrm{G}=0.015$, variance $=0.000001, \mathrm{z}=12.823$, $p<0.05$ ). No significant positive spatial autocorrelation (Moran's $I=0.038, \mathrm{z}=0.286, p>0.05$ ) was observed for $F$. hepatica.

Regarding $D$. viviparus, the spatial distribution of negative and positive farms was significantly different (Fig. 2): for latitude $p<0.05$ and 0 for longitude $p<0.05$. Significant differences, with higher percentage of positive farms were found in the annual precipitation, specifically in the categories of 2000 to $4000 \mathrm{~mm}$, as well as in the basal altitudinal belt, in the life zone variable of Moist Forest, and in the category of $>24^{\circ} \mathrm{C}$ of biotemperature variable (Table 1 ). 


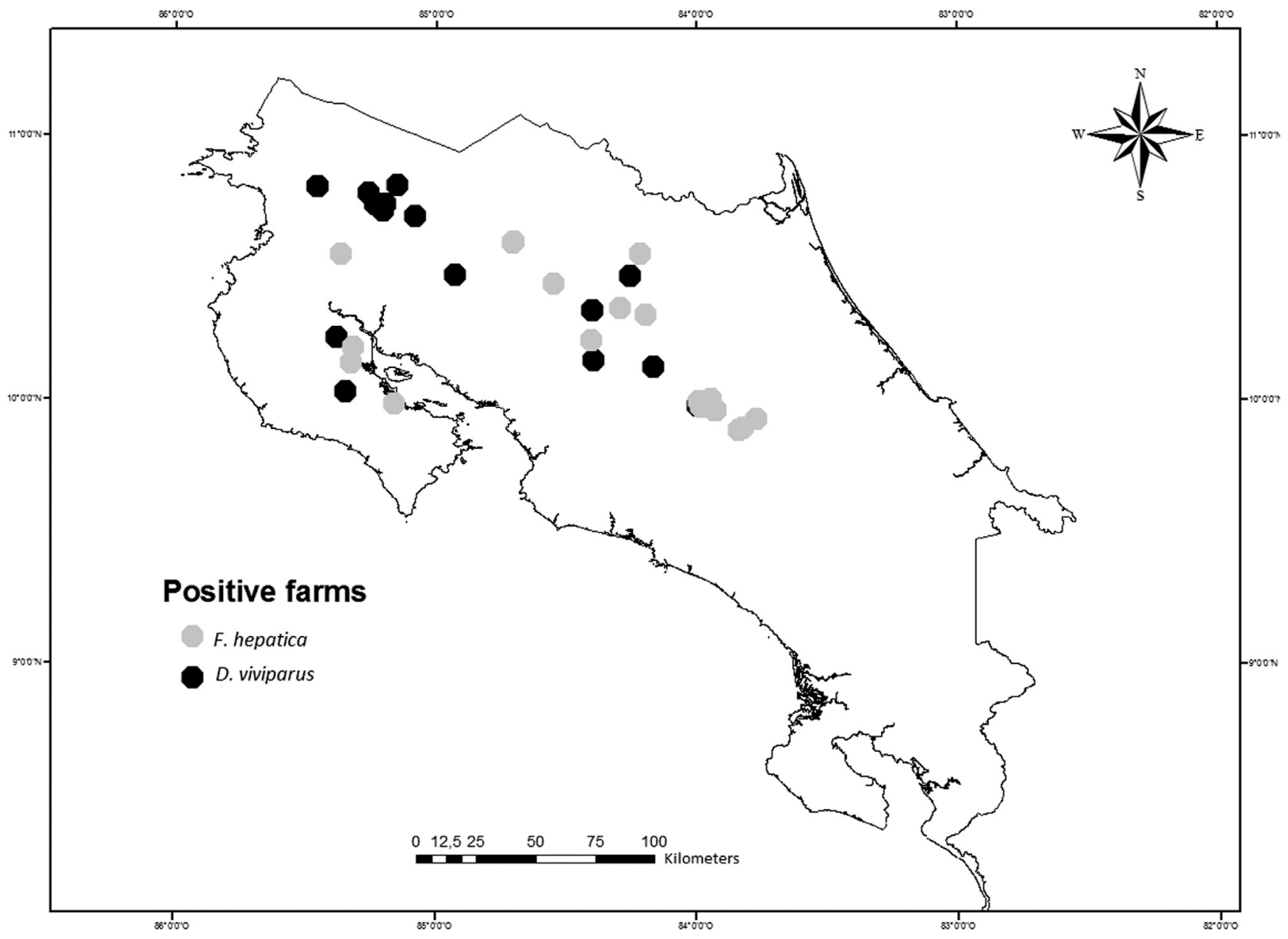

Fig. 1. Distribution of infected dairy herds for Dictyocaulus viviparus and Fasciola hepatica in Costa Rica.

On the other hand, significant difference was found for $F$. hepatica in the latitude of farms $(p<0.05)$, but not in longitude $(p>0.05)$ (Fig. 3). Significant differences were found soil orders of Alfisol and Vertisols, as well as in precipitation in the category of $<2000 \mathrm{~mm}$; finally in the elevation variable in the category of 1201 to 1800 m.a.s.l. a significant difference was found (Table 2).

\section{Discussion}

The ELISA tests carried out in bulk milk tank samples have been used for many years for monitoring infectious diseases (Forschner et al., 1986; Niskanen, 1993; Hoorfar et al., 1995), and parasitic diseases (Björkman et al., 1997; Bennema et al., 2009; Fiedor et al., 2009); however, this is the first report of $D$. viviparus and $F$. hepatica prevalence at the herd level, determined with milk tank samples in Costa Rica.

Most reports on D. viviparus and $F$. hepatica prevalence determined in bulk milk tank samples were from temperate countries, where prevalences for the first parasite presented ranges between $2.6 \%$ and 31.2\% (Bennema et al., 2009; Fiedor et al., 2009; Schunn et al., 2013; Ploeger et al., 2014; Dank et al., 2015), while prevalences for the second agent were determined ranging between $6.5 \%$ and $75.4 \%$ (Bennema et al., 2009; Höglund et al., 2010; Bloemhoff et al., 2015). In Costa Rica, the prevalence of $D$. viviparus obtained in this study (3.8\%) was low with respect to that reported by Jiménez et al. (2008) ranging between $15 \%$ and $44 \%$ in different farms, whereas the prevalence of $F$. hepatica (3.6\%) was slightly higher than the $1.9 \%$ reported by Rojas (2015). For D. viviparus, the greatest percentage of positive farms was found in the Chorotega region (13\%), which is statistically significant and may be related to the variables of precipitation, altitude, life zone and biotemperature, that showed a significant difference between $D$. viviparus positive and negative farms; or eventually to management variables in farms, which were however, not analyzed in this study, but reported previously (Jiménez et al., 2010). The presence of this parasite in dairy farms located in the counties of Liberia, Hojancha and Nicoya of the Chorotega region is reported for the first time in Costa Rica.

For $F$. hepatica, the highest percentage of positive farms was found in the Central region (5.63\%), with no statistically significant difference between the regions. However, positive farms were found in the county of Turrialba in this region, where several cases have been reported in humans and in bovines (Mora et al., 1980; Chang and Cartín, 1983; Alpízar et al., 2013; Rojas, 2015). In addition, a study of $F$. hepatica prevalence in the Central and Caribbean regions found the highest number of positive animals, which came from places with a high probability of infection (Rojas, 2015).

The use of GIS in this study made it possible to analyze environmental variables as possible explanations for $D$. viviparus and $F$. hepatica spatial distribution. The analysis revealed differences in spatial distribution of positive farms when comparing both parasites, as well as when comparing farms that were positive and negative for each agent. This finding may be related to variations in latitude and longitude, which are related to environmental conditions such as temperature, precipitation, and life zone, or may be related to differences in the management practices in the regions, which are important characteristics in determining presence or absence of the parasites (Bennema et al., 2009; Khan et al., 2009). A risk-predictive factor for both agents is precipitation, which has been used in different studies for the construction of risk models (McCann et al., 2010; Selemetas et al., 2015).

In this study, presence of $D$. viviparus was related to forests with average annual precipitations ranging between 2000 and $4000 \mathrm{~mm}$, and a dry season between 0 and 5 months, in contrast to dry forest 


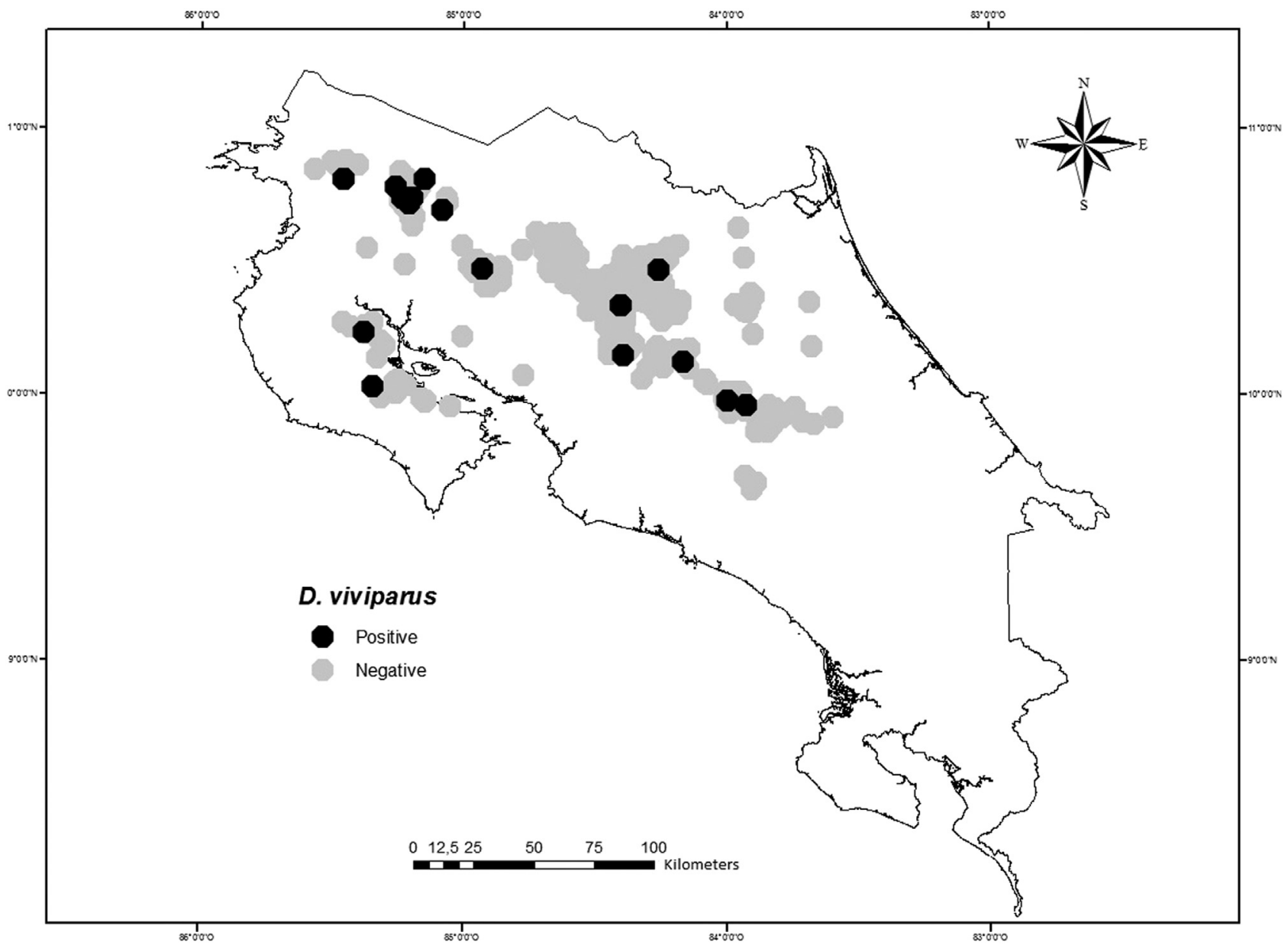

Fig. 2. Distribution of infected dairy herds for Dictyocaulus viviparus in Costa Rica.

characteristics (1000 to $2000 \mathrm{~mm}$ average annual precipitation, and seven months of dry season), and other types of forests in Costa Rica, where there is practically no dry season. Studies carried out by Jiménez et al. (2007) reported that precipitation had a significant effect on $D$. viviparus prevalence where average annual precipitation was $3333 \mathrm{~mm}$, a value which is within the ranges found in this study. Precipitation conditions may favor survival of larvae, since they are found in excrement, which is susceptible to desiccation. Excess precipitation may also be an unfavorable condition for larvae, causing them to come into hypobiosis.

Fasciola hepatica has as the primary intermediate host the snail of the genus Lymnaea, whose distribution is determined by its requirements for specific humidity and vegetation (Pritchard et al., 2005; Bennema et al., 2009; Freitas et al., 2014). The environmental variables

Table 1

Environmental variables with significant differences between positive and negative farms for $D$. viviparus.

\begin{tabular}{|c|c|c|c|c|c|c|}
\hline Variable & Category & Positives & Total & Percentage & $\chi^{2}$ & $\mathrm{P}$ \\
\hline \multirow[t]{3}{*}{ Soils } & Alfisols + Vertisols & 2 & 23 & 8.70 & 2.73 & $>0.05$ \\
\hline & Inceptisol & 18 & 461 & 3.90 & & \\
\hline & Ultisol & 0 & 32 & 0.00 & & \\
\hline \multirow[t]{3}{*}{ Precipitation (mm) } & $<2000$ & 1 & 63 & 1.59 & 5.75 & $>0.05$ \\
\hline & $2000-4000$ & 17 & 306 & 5.56 & & \\
\hline & $>4000$ & 2 & 148 & 1.35 & & \\
\hline \multirow[t]{4}{*}{ Altitudinal belt } & Basal & 11 & 142 & 7.75 & 8.19 & $<0.05$ \\
\hline & Montane & 0 & 5 & 0.00 & & \\
\hline & Lower Montane & 4 & 132 & 3.03 & & \\
\hline & Premontane & 5 & 238 & 2.10 & & \\
\hline \multirow[t]{3}{*}{ Life zone } & Moist Forest & 9 & 103 & 8.74 & 8.72 & $<0.05$ \\
\hline & Wet Forest & 11 & 383 & 2.87 & & \\
\hline & Rain Forest & 0 & 29 & 0.00 & & \\
\hline \multirow[t]{3}{*}{ Biotemperature $\left({ }^{\circ} \mathrm{C}\right)$} & $<18$ & 4 & 137 & 2.92 & 8.07 & $<0.05$ \\
\hline & $18-24$ & 5 & 238 & 2.10 & & \\
\hline & $>24$ & 11 & 142 & 7.75 & & \\
\hline \multirow[t]{4}{*}{ Elevation (m.a.s.l) } & $\leq 600$ & 7 & 254 & 2.76 & 11.79 & $>0.05$ \\
\hline & $600-1200$ & 9 & 96 & 9.38 & & \\
\hline & $1201-1800$ & 2 & 87 & 2.30 & & \\
\hline & $>1800$ & 2 & 82 & 2.44 & & \\
\hline
\end{tabular}




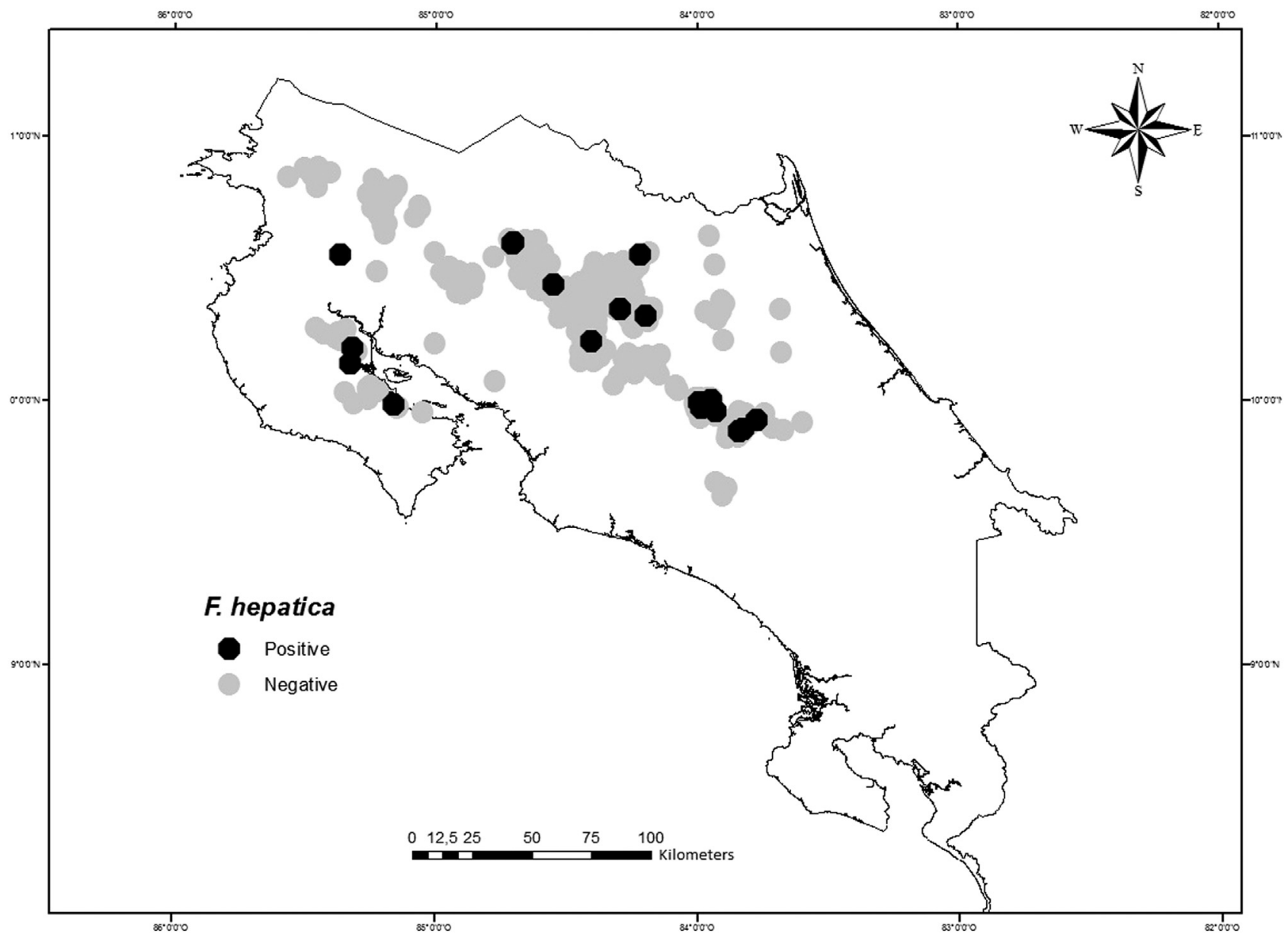

Fig. 3. Distribution of infected dairy herds for Fasciola hepatica in Costa Rica.

Table 2

Environmental variables with significant differences between positive and negative farms for $F$. hepatica.

\begin{tabular}{|c|c|c|c|c|c|c|}
\hline Variable & Category & Positives & Total & Porcentage & $\chi^{2}$ & $\mathrm{P}$ \\
\hline \multirow[t]{3}{*}{ Soils } & Alfisols + Vertisols & 5 & 23 & 21.74 & 26.11 & $<0.05$ \\
\hline & Inceptisol & 11 & 459 & 2.40 & & \\
\hline & Ultisol & 3 & 32 & 9.38 & & \\
\hline \multirow[t]{3}{*}{ Precipitation (mm) } & $<2000$ & 6 & 63 & 9.52 & 6.89 & $<0.05$ \\
\hline & $2000-4000$ & 9 & 306 & 2.94 & & \\
\hline & $>4000$ & 4 & 146 & 2.74 & & \\
\hline \multirow[t]{4}{*}{ Altitudinal belt } & Basal & 4 & 140 & 2.86 & 5.02 & $>0.05$ \\
\hline & Montane & 0 & 5 & 0.00 & & \\
\hline & Lower Montane & 9 & 132 & 6.82 & & \\
\hline & Premontane & 6 & 238 & 2.52 & & \\
\hline \multirow[t]{3}{*}{ Life zone } & Moist Forest & 7 & 103 & 6.80 & 3.48 & $>0.05$ \\
\hline & Wet Forest & 11 & 381 & 2.89 & & \\
\hline & Rain Forest & 1 & 29 & 3.45 & & \\
\hline \multirow[t]{3}{*}{ Biotemperature $\left({ }^{\circ} \mathrm{C}\right)$} & $<18$ & 9 & 137 & 6.57 & 4.39 & $>0.05$ \\
\hline & $18-24$ & 6 & 238 & 2.52 & & \\
\hline & $>24$ & 4 & 140 & 2.86 & & \\
\hline \multirow[t]{4}{*}{ Elevation (m.a.s.l) } & $\leq 600$ & 10 & 251 & 3.98 & 8.71 & $<0.05$ \\
\hline & $600-1200$ & 0 & 95 & 0.00 & & \\
\hline & $1201-1800$ & 7 & 87 & 8.05 & & \\
\hline & $>1800$ & 2 & 82 & 2.44 & & \\
\hline
\end{tabular}

which showed significantly different values between $F$. hepatica positive and negative farms were soil type (Alfisols and Vertisols), annual precipitation < $2000 \mathrm{~mm}$ and elevation from 1201 to 1800 m.a.s.l. The types of soil that showed significant differences with respect to the presence or absence of $F$. hepatica, presented some characteristics that could contribute to the creation of optimal environments for the survival of snails. Snails require clay soils that accumulate a great amount of moisture, and that contain minerals such as calcium (Vertisols) needed to form shells (Morales and Pino, 2004; Schnieder, 2006; Deplazes et al., 2013). Some studies have found that soil characteristics may be predictive factors for fasciolosis (McCann et al., 2010; Selemetas et al., 2014; Selemetas et al., 2015). Selemetas et al. (2015) found that regions that were positive for the disease had deep soils with poor drainage, which is consistent with the characteristics of soils of 
positive regions in Costa Rica, which have poor drainage and may flood during the rainy season. In relation to the significant variables of altitude and precipitation found in this study, the presence of $F$. hepatica has been associated elsewhere with environmental factors (precipitation, temperature, moist, presence of ponds or flows of water, soil type, vegetation type, type of snail habitat, presence of snails, presence of bodies of water, and pasture drainage) (Howell et al., 2015).

\section{Conclusion}

Spatial distribution of positive farms for D. viviparus showed significant clustering in contrast with the distribution of positive farm for F. hepatica. This distribution may be associated with environmental variables that were statistically related to both parasites. Precipitation, altitudinal belt, life zone and biotemperature were environmental variables associated to $D$. viviparus, whereas soil, precipitation and elevation were for $F$. hepatica. The results of the analysis of the environmental variables can be used in the future as an input in the construction of risk maps. It is recommended investigate the possible relationships of the presence of parasites with other environmental characteristics not considered in this study, such as humidity, soil $\mathrm{pH}$, type of vegetation, and presence of water bodies. Likewise, variables related to management, such as grazing duration, deworming program, which have been reported in other latitudes, and have shown to be related to significant risks for $D$. viviparus and $F$. hepatica, should also be studied in detail.

\section{Acknowledgements}

We are very thankful to the Vicerrectoría de Investigación, Universidad Nacional, for financial support. We also thank the German Service of Academic Exchange (DAAD) for the research scholarship given to Victor Montenegro, M.Sc. Manrique Oviedo for the sample collection, and Sandra Buschbaum for the technical assistance. The collaboration of farm owners is also gratefully acknowledged.

\section{References}

Alpízar, C., Bianque de Oliveira, J., Jiménez, A.E., Hernández, J., Berrocal, A., Romero, J.J., 2013. Fasciola hepatica en ganado bovino de carne en Siquirres y lesiones anatomo-histopatológicas de hígados bovinos decomisados en mataderos de Costa Rica. Agron. Costarric. 37, 7-16.

Arroyo, R., Mora, J., Molina, S., Troper, L., Amador, A., 1981. Fascioliasis hepatica humana en Costa Rica. Rev. Costarric. Cienc. Méd. 2, 35-57.

Bennema, S., Vercruysse, J., Claerebout, E., Schnieder, T., Strube, C., Ducheyne, E., Charlier, J., 2009. The use of bulk-tank milk ELISA to assess the spatial distribution of Fasciola hepatica, Ostertagia ostertagi and Dictyocaulus viviparus in dairy cattle in Flanders (Belgium). Vet. Parasitol. 165, 51-57.

Bennema, S., Ducheyne, E., Vercruysse, J., Claerebout, E., Hendrickx, G., Charlier, J., 2011. Relative importance of management, meteorological and environmental factors in the spatial distribution of Fasciola hepatica in dairy cattle in a temperate climate zone. Int. J. Parasitol. 41, 225-233.

Björkman, C., Holmdahl, O.J., Uggla, A., 1997. An indirect enzyme-linked immunoassay (ELISA) for demonstration of antibodies to Neospora caninum in serum and milk of cattle. Vet. Parasitol. 68, 251-260.

Bloemhoff, Y., Forbes, A., Good, B., Morgan, E., Mulcahy, G., Strube, C., Sayers, R., 2015. Prevalence and seasonality of bulk milk antibodies against Dictyocaulus viviparus and Ostertagia ostertagi in Irish pasture-based dairy herds. Vet. Parasitol. 209, 108-116.

Chang, E., Cartín, M.E., 1983. Diagnosis and control of bovine fascioliasis in Santa Cruz de Turrialba District, Cartago Province. Cienc. Vet. 5, 118.

Charlier, J., Duchateau, L., Claerebout, E., Williams, D., Vercruysse, J., 2007. Associations between anti-Fasciola hepatica antibody levels in bulk-tank milk samples and production parameters in dairy herds. Prev. Vet. Med. 78, 57-66.

Cornelissen, J.B.W.J., Borgsteede, F.H.M., Van Milligen, F.J., 1997. Evaluation of an ELISA for the routine diagnosis of Dictyocaulus viviparus infections in cattle. Vet. Parasitol. 70, 153-164.

Dank, M., Holzhauer, M., Veldhuis, A., Frankena, K., 2015. Association between Dictyocaulus viviparus status and milk production parameters in Dutch dairy herds. J. Dairy Sci. 98, 7741-7747.

Das Chagas, C., Batista, M., Vilhena, I., Rauta de Avelar, B., Salim, M., Molinari, D., 2011. Prevalence of liver condemnation due to bovine fasciolosis in Southern Espírito Santo: temporal distribution and economic losses. Rev. Bras. Parasitol. Vet. 20, 49-53.

Deplazes, P., Eckert, J., von Samson-Himmelstjerna, G., Zahner, H., 2013. Lehrbuch der
Parasitologie für die Tiermedizine, 3 edición. Enke, Stuttgart, Duitsland (625 pp).

Dracz, R.M., Lima, W.D.S., 2014. Autochthonous infection of buffaloes and cattle by Fasciola hepatica in Minas Gerais, Brazil. Rev. Bras. Parasitol. Vet. 23, 413-416.

Fiedor, C., Strube, C., Forbes, A., Buschbaum, S., Klewer, A.M., von SamsonHimmelstjerna, G., Schnieder, T., 2009. Evaluation of a milk ELISA for the serodiagnosis of Dictyocaulus viviparus in dairy cows. Vet. Parasitol. 166, 255-261.

Forschner, E., Bunger, I., Kuttler, D., Merkhens, L., 1986. IBR/IPV — serologic diagnosis, using blood-samples, single milk samples and bulk milk samples, control of cattle herds eradication by separation or vaccination. Deut Tierarztl Woch. 93, 328-335.

Freitas, D.F., Martins, I.V., dos Santos, G.M., dos Santos, A.R., da Silva Gomes, D., 2014 Bioclimatic distribution and prevalence maps for Fasciola hepatica in Espírito Santo State, Brazil. J. Venom. Anim. Toxins. 20, 32.

Höglund, J., Dahlström, F., Engström, A., Hessle, A., Jakubek, E.B., Schnieder, T., Sollenberg, S., 2010. Antibodies to major pasture borne helminth infections in bulktank milk samples from organic and nearby conventional dairy herds in south-central Sweden. Vet. Parasitol. 171, 293-299.

Holdridge, L., 1978. Ecology Based on Life Zones. American Institute of Agricultural Sciences (IICA), San José, Costa Rica.

Holzhauer, M., Van Schaik, G., Saatkamp, H.W., Ploeger, H.W., 2011. Lungworm outbreaks in adult dairy cows: estimating economic losses and lessons to be learned. Vet. Rec. 169, 494.

Hoorfar, J., Lind, P., Bitsch, V., 1995. Evaluation of an O antigen enzyme-linked im munosorbent assay for screening of milk samples for Salmonella dublin infection in dairy herds. Can. J. Vet. Res. 59, 142-148.

Howell, A., Baylis, M., Smith, R., Pinchbeck, G., Williams, D., 2015. Epidemiology and impact of Fasciola hepatica exposure in high-yielding dairy herds. Prev. Vet. Med. 121, 41-48.

Issia, L., Pietrokovsky, S., Sousa-Figueiredo, J., Stothard, J.R., Wisnivesky-Colli, C., 2009. Fasciola hepatica infections in livestock flock, guanacos and coypus in two wildlife reserves in Argentina. Vet. Parasitol. 165, 341-344.

Jiménez, A.E., Montenegro, V.M., Hernández, J., Dolz, G., Maranda, L., Galindo, J., Schnieder, T., 2007. Dynamics of infections with gastrointestinal parasites and Dictyocaulus viviparus in dairy and beef cattle from Costa Rica. Vet. Parasitol. 148, $262-271$.

Jiménez, A.E., Fernández, A., Dolz, G., Vargas, B., Epe, C., Schnieder, T., 2008. Dictyocaulus viviparus seroprevalence and epidemiology in Costa Rican dairy cattle. Vet. Parasitol. 154, 294-299.

Jiménez, A.E., Fernández, A., Alfaro, R., Dolz, G., Vargas, B., Epe, C., Schnieder, T., 2010 A cross-sectional survey of gastrointestinal parasites with dispersal stages in feces from Costa Rican dairy calves. Vet. Parasitol. 173, 236-246.

Kajugu, P.E., Hanna, R.E.B., Edgar, H.W., McMahon, C., Cooper, M., Gordon, A., Fairweather, I., 2015. Fasciola hepatica: specificity of a coproantigen ELISA test for diagnosis of fasciolosis in faecal samples from cattle and sheep concurrently infected with gastrointestinal nematodes, coccidians and/or rumen flukes (paramphistomes), under field conditions. Vet. Parasitol. 212 (3), 181-187.

Khan, M.K., Sajid, M.S., Khan, M.N., Iqbal, Z., Iqbal, M.U., 2009. Bovine fasciolosis: prevalence, effects of treatment on productivity and cost benefit analysis in five districts of Punjab, Pakistan. Res. Vet. Sci. 87, 70-75.

Kuerpick, B., Conraths, F.J., Staubach, C., Froehlich, A., Schnieder, T., Strube, C., 2013a. Seroprevalence and GIS-supported risk factor analysis of Fasciola hepatica infections in dairy herds in Germany. Parasitology 140, 1051-1060.

Kuerpick, B., Schnieder, T., Strube, C., 2013b. Evaluation of a recombinant cathepsin L1 ELISA and comparison with the Pourquier and ES ELISA for the detection of antibodies against Fasciola hepatica. Vet. Parasitol. 193, 206-213.

McCann, C.M., Baylis, M., Williams, D.J., 2010. The development of linear regression models using environmental variables to explain the spatial distribution of Fasciola hepatica infection in dairy herds in England and Wales. Int. J. Parasitol. 40, 1021-1028.

Mora, J., Arroyo, R., Molina, S., Troper, L., Irías, E., 1980. Nuevos aportes sobre el valor de la fasciolina. Estudio en un área endémica de Costa Rica. Bol. Oficina Sanit. Panam. 89, 409-414.

Morales, G., Pino, L., 2004. Fasciola hepatica y Distomatosis hepatica bovina en Venezuela. Red de Helmintología de FAO para América Latina y el Caribe: Contribución a la Conferencia Electrónica. (19 pp).

Niskanen, R., 1993. Relationship between the levels of antibodies to bovine viral diarrhoea virus in bulk milk tank and the prevalence of cows exposed to the virus. Vet. Rec. 133, 341-344.

Olsen, A., Frankena, K., Toft, N., Thamsborg, S.M., Enemark, H.L., Halasa, T., 2015 Prevalence, risk factors and spatial analysis of liver fluke infections in Danish cattle herds. Parasit.Vectors. 8, 160.

Ploeger, H.W., Holzhauer, M., Uiterwijk, M., Van Engelen, E., 2014. Comparison of two serum and bulk-tank milk ELISA for diagnosing natural (sub) clinical Dictyocaulus viviparus infection in dairy cows. Vet. Parasitol. 199, 50-58.

Pritchard, G.C., Forbes, A.B., Williams, D.J., Salimi-Bejestani, M.R., Daniel, R.G., 2005. Emergence of fasciolosis in cattle in East Anglia. Vet. Rec. 157, 19.

Pyziel, A.M., Laskowski, Z., Höglund, J., 2015. Development of a multiplex PCR for identification of Dictyocaulus lungworms in domestic and wild ruminants. Parasitol. Res. 114, 3923-3926.

Radfar, M.H., Nourollahi-Fard, S.R., Mohammadyari, N., 2015. Bovine fasciolosis: prevalence, relationship between faecal egg count and worm burden and its economic impact due to liver condemnation at Rudsar abattoir, Northern Iran. J. Parasit. Dis. 39.

Rojas, D., 2015. Prevalencia de Fasciola hepatica en bovinos sacrificados en mataderos de clase A de Costa Rica durante el 2014. Tesis de maestría para optar por el grado de Magister Science con énfasis en Epidemiología. Posgrado Regional en Ciencias Veterinarias. Universidad Nacional, Heredia, Costa Rica, pp. 52-66. 
Salimi-Bejestani, M.R., Mcgary, J.W., Felstead, S.M., Ortiz, P., Akca, A., Williams, D.J.L., 2005. Development of an antibody-detection ELISA for Fasciola hepatica and its evaluation against a commercially available test. Res. Vet. Sci. 78, 177-181.

Schnieder, T., 1992. Use of a recombinant Dictyocaulus viviparus antigen in an enzymelinked immunosorbent assay for immunodiagnosis of bovine dictyocaulosis. Parasitol. Res. 78, 298-302.

Schnieder, T., 2006. Veterinärmedizinische Parasitologie, 6 Edition. Parey, Stuttgart, Duitsland (773 pp).

Schunn, A.M., Forbes, A., Schnieder, T., Strube, C., 2012. Validation of a Dictyocaulus viviparus MSP-ELISA and cut-off adjustment in a one-year longitudinal field study in dairy cattle herds. Vet. Parasitol. 189, 291-298.

Schunn, A.M., Conraths, F.J., Staubach, C., Fröhlich, A., Forbes, A., Schnieder, T., Strube, C., 2013. Lungworm infections in German dairy cattle herds-Seroprevalence and
GIS-supported risk factor analysis. PLoS One 8, e74429.

Sekiya, M., Zintl, A., Doherty, M.L., 2013. Bulk milk ELISA and the diagnosis of parasite infections in dairy herds: a review. Ir. Vet. J. 66, 14.

Selemetas, N., Phelan, P., O'Kiely, P., de Waal, T., 2014. Weather and soil type affect incidence of fasciolosis in dairy cow herds. Vet. Rec. 175, 371.

Selemetas, N., Ducheyne, E., Phelan, P., O'Kiely, P., Hendrickx, G., de Waal, T., 2015. Spatial analysis and risk mapping of Fasciola hepatica infection in dairy herds in Ireland. Geospat. Health 9, 281-291.

Von Holtum, C., Strube, C., Schnieder, T., von Samson-Himmelstjerna, G., 2008. Development and evaluation of a recombinant antigen-based ELISA for serodiagnosis of cattle lungworm. Vet. Parasitol. 151, 218-226.

Wapenaar, W., 2011. Preventing lungworm. Vet. Rec. 169, 491-492. 